\title{
Derleme /Review \\ Nitrik Oksit Uygulamalarının Bitkilerde Abiyotik Stres Şartlarına Toleransı Arttırmadaki Etkileri
}

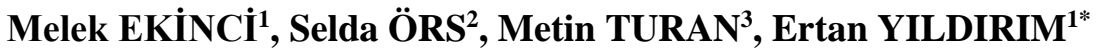 \\ ${ }^{1}$ Atatürk Üniversitesi, Ziraat Fakültesi, Bahçe Bitkileri Bölümü, Erzurum, Türkiye \\ ${ }^{2}$ Atatürk Üniversitesi, Ziraat Fakültesi, Tarımsal Yapılar ve Sulama Bölümü, Erzurum, Türkiye \\ ${ }^{3}$ Yeditepe Üniversitesi, Mühendislik ve Mimarlık Fakültesi, Genetik ve Biyomühendislik Bölümü, İstanbul, Türkiye \\ *sorumlu yazar: ertanyil@atauni.edu.tr; Tel: +90 (442) 2312718 / Fax: +90 (442) 2360958
}

\begin{abstract}
Özet: Günümüzde bitkisel üretimini sınırlandıran çevresel stres faktörleri nedeniyle, yetiştiricilikte bitkinin normal ürün potansiyeline ulaşmasını sağlayacak uygun alanların bulunması oldukça zorlaşmışıtır. Tarımsal üretimin azalmasında çok büyük oranda abiyotik stres, daha düşük oranlarda ise diğer stres faktörleri etkilidir. Abiyotik stres faktörleri olarak, kuraklık, tuzluluk, yüksek ve düşük sıcaklık, sel, radyasyon, ağır metaller, oksidatif stres, rüzgâr, besin maddesi eksikliği gibi faktörler sayılabilir ve bu stres kaynakları bitki gelişimini, kaliteyi ve verimliliği olumsuz yönde etkilemektedir. Gaz halindeki farklı bileşikler arasında, nitrik oksitin (NO) bitkilere dışarıdan uygulanması son yıllarda daha fazla önem kazanmıştır. NO tohum çimlenmesi ve fide büyümesinin iyileştirilmesi gibi bitkilerde düzenleyici rollerinin yanı sıra, metal toksisitesi, sıcaklık, kuraklık ve tuzluluk gibi farklı abiyotik streslere karşı da koruyucu bir rol oynamaktadır. Bu makalede bitkilerin kuraklık, tuzluluk, yüksek ve düşük sıcaklık ile ağır metaller gibi abiyotik stres koşullarında NO uygulamalarının etkileri tartışılmıştır.
\end{abstract}

Anahtar Kelimeler: Abiyotik stres, Bitki gelişimi, Nitrik oksit, Tolerans

\section{Effects of Nitric Oxide Applications on Tolerance of Plants in Abiotic Stress Conditions}

\begin{abstract}
Due to the major environmental stress factors that limit crop production today, finding suitable areas where the plant can reach the normal crop potential in cultivation has become very difficult. Abiotic stress is a significant factor in decreasing the agricultural production as compared to the other stress factors. Abiotic stress factors, such as drought, salinity, high temperature, low temperature, flooding, radiation, pollutants, oxidative stress, wind and lack of nutrients in the soil, can negatively affect the growth, development and productivity of plants. Among the compounds with different gas contents, external application of nitric oxide (NO) to plants has gained more importance in recent years. NO plays a protective role against different abiotic stresses such as metal toxicity, temperature, drought and salinity, as well as regulatory roles in improvement of germination and seedling growth. This paper discusses the effects of $\mathrm{NO}$ applications on abiotic stress conditions such as drought, salinity, high and low temperature and heavy metals on plants.
\end{abstract}

Keywords: Abiotic stress, Plant growth, Nitric oxide, Tolerance

\section{Giriş}

Bitkiler yaşamlarını sürdürdükleri alanlarda, gelişimlerini kısıtlayıcı çeşitli olumsuz koşullara maruz kalmaktadırlar. Bitkilerde büyüme, gelişme ve metabolizmayı etkileyen ya da engelleyen durumlara stres adı verilmektedir (Gürel ve Avcıoğlu 2001). İklim değişiminin devam etmesi ve ekstrem iklim koşullarının artışı nedeniyle Dünya'nın bir çok bölgesinde bitkisel üretim üzerine çevresel stres faktörlerinin olumsuz etkisinin artacağı bildirilmektedir (Denby ve Gehring 2005). Stres faktörleri, bitkiler üzerine etkilerini çoğunlukla eş zamanlı şekilde gösterebilmektedirler (Kalefetoğlu ve Ekmekçi 2005). Bu faktörler orijinlerine göre abiyotik ve biyotik stres faktörleri olmak üzere iki grupta incelenebilmektedir. Biyotik strese yaşayan organizmalar neden olurken, abiyotik stres faktörleri, kuraklık, tuzluluk, yüksek ve düşük sıcaklık, radyasyon, ağır metaller, besin maddesi eksikliği, oksidatif stres, rüzgâr, gibi çevresel etkenlere bağlıdır. Tarımsal üretimin azalmasında \%71 oranında abiyotik stres, \%29 oranında ise diğer stres faktörleri etkili olmaktadır (Boyer 1982). 
Dünya'da ekilebilir alanların yalnızca \%10'unun bazı stres formlarından uzak olduğu tahmin edilmektedir. Potansiyel verim ile elde edilen verim arasındaki farktan çevresel stres faktörleri sorumludur. Abiyotik stres faktörlerinin, Dünya'da bitkisel üretimi sınırlayan başlıca etken olduğu ve çoğu ürünün veriminde \%50'den fazla azalmaya neden olduğu rapor edilmiştir (Mahajan ve Tuteja 2005). Son on yılda başlıca stres faktörlerinin etkisini azaltmak için farklı sulama teknikleri, toprak iyileştirmesi ve uygun gübre kullanımı gibi çalışmalar yoğunluk kazanmıştır. Farklı bir yaklaşım olarak bitki gelişim süresince bitkiye dışarıdan uygulanan bazı iyileştiricilerin kullanımı da son yıllarda denenmeye başlanmış ve nitrik oksit (NO) kullanılan uygulamaların bitkide stres toleransını artırıcı etkiye sahip olabileceği gözlenmiştir.

NO’nun bitkilere dışarıdan uygulandığında tohum çimlenmesi ve fide büyümesinin iyileştirilmesi gibi bitkilerde düzenleyici rollerinin yanı sıra (Habib ve ark. 2010), metal toksisitesi, sicaklık, kuraklık (Garcia-Mata ve Lamattina 2001; Wu ve ark. 2011; Liu ve ark. 2013; Esim ve Atici 2014) ve tuzluluk (Habib ve ark. 2010, 2013; Begara-Morales ve ark. 2014; Ali ve ark. 2017; Arasimowicz ve Floryszak-Wieczorek 2007) gibi farklı abiyotik streslere karşı da koruyucu bir rol oynamaktadır.

Bu çalışmada, bitki büyüme ve gelişmesinde önemli etkileri olan bazı abiyotik stres faktörlerine karşı NO’nun bitki gelişimi ve fizyolojisi üzerine etkileri daha önce yapılan çeşitli araştırmalar neticesinde elde edilen bulgular doğrultusunda verilmiştir.

\section{NO ve Bitki Fizyolojisindeki İşlevi}

NO doğada uçucu, lipofilik serbest radikal olup (Hayat ve ark. 2010), antioksidan görevi görür (Kausar ve Shahbaz 2013). Son on yıl içinde tıp, biyokimya, fizyoloji ve genetik dahil olmak üzere bilimin neredeyse tüm dallarında özel ilgi gören bir molekül olmuştur. NO, stres koşullarında bitkilerde fizyolojik bir cevap olarak üretilen bir sinyal molekülüdür. NO bitkilerde, tohum çimlenmesi, primer ve lateral kök büyümesi, çiçeklenme, polen tüpü büyümesi regülasyonu, meyve olgunlaşması, yaşlanma, faydalı bitki- mikrobiyal etkileşimler, savunma tepkileri gibi birçok süreçte yer alır. NO aynı zamanda peroksinitrit (ONOO-) ve S- dahil NO türevli moleküller tarafından aracıllk edilen nitrasyon ve S-nitrozilasyon gibi post-translasyonel modifikasyonlar (PTM'ler) boyunca birçok proteinin fonksiyonunu etkileyen farklı hücre içi süreçlerde önemli bir sinyal molekülüdür (Małgorzata Kopyra 2004).

Bitkiler, sirkadiyen ve mevsimsel çevre koşullarındaki dalgalanmalara tepki veren yerleşik mekanizmalara sahiptir. Abiyotik stresler oksidatif strese veya reaktif oksijen türlerinin ROS (Reactive Oxygen Species) oluşumuna yol açan hücresel redoks dengesini bozmaktadır. Oksidatif stres sırasında, bitki hücresinin farklı yerlerinde (mitokondri, kloroplast, peroksizom ve nükleus) meydana gelen ROS oluşumu yaralanma ve hücre ölümüne neden olur. Öte yandan ROS, hücre içi redoks sinyal sistemleri ve antioksidan direnç mekanizmalarının aktivasyonunda hayati bir rol oynar. NO molekülünde eşlenmemiş bir elektronun varlığı onu reaktif bir tür yapar. NO’nun ROS ile kombinasyonu, koşullara bağlı olarak toksik veya koruyucu olarak tanımlanabilir. Düşük miktarlarda mevcut olduğunda, ROS savunma yanıtlarının aktivasyonu için sinyal görevi görür. Bununla birlikte, kontrolsüz ROS üretimi tarafindan üretilen yüksek konsantrasyonlarda ciddi zararlanmalara neden olabilir. Bu anlamda NO, bitkilerde aynı anda farklı fizyolojik fonksiyonlar ve savunma mekanizmalarında rol almada biyokimyasal reaktiviteye sahiptir (Małgorzata Kopyra 2004). Bitkilerde NO’nun sinyal rolünün, normal ve stres koşullarında bitki büyümesini regüle ettiği de bildirilmiştir (Arora ve Bhatla 2017).

Hücresel zararlanmanın ağırlıklı olarak ROS'dan kaynaklandığı bir sistemde NO, bir zincir kırıcı görevi görebilir ve böylece hasarı sınırlayabilir (Lipton ve ark. 1993). NO, ROS'un modülasyonuna aracılık eder ve çeşitli abiyotik streslere maruz kalan bitkilerde antioksidan savunma sistemlerini geliştirir (Siddiqui ve ark. 2011). NO, ROS ve hormonların seviyesini ve toksisitesini düzenleyerek, aynı zamanda sinyal iletimi, savunma ve hücre ölümü, taşınım, temel metabolizma ile ROS üretimi ve parçalanması gibi farklı süreçleri kontrol eden genlerin ifadesini indükleyerek hücresel koruyucu olarak önemli bir rol oynamaktadır (Şekil 1) (Siddiqui ve ark. 2011). 

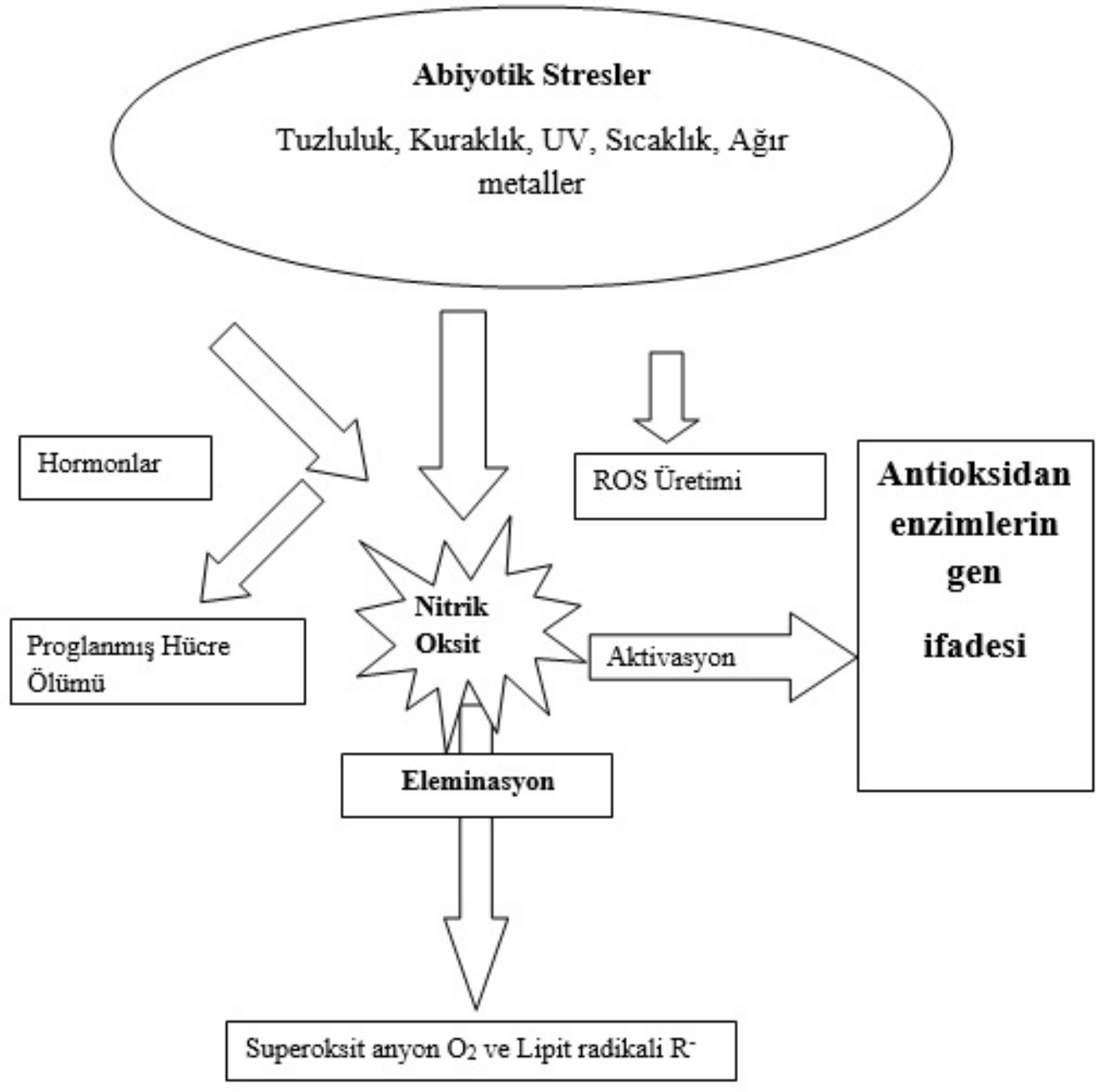

Şekil 1. Abiyotik strese karşı bitki toleransında nitrik oksit aracılı sinyal yolu için genelleştirilmiş bir model (Siddiqui ve ark. 2011)

NO, bitkilerde meydana gelen ve normalde bitki patojen etkileşimi sırasında ROS oluşumuna bağlanan hücre ölümü, iyon sızıntısı ve DNA fragmantasyonu dolayısıyla gen ifadesini düzenlemek gibi diğer olayları da etkileyebilmektedir (Arasimowicz ve Floryszak-Wieczorek 2007; Corpas ve Barroso 2015).

\section{Tuzluluk ve Nitrik Oksit Uygulamalart}

Aşırı toprak tuzluluğu, dünya çapında ürün verimliliğini ciddi ölçüde kısıtlayan en yaygın abiyotik stres faktörlerinden biridir. Tuzluluk kurak ve yarı kurak bölgelerde 110 milyon hektar alanı etkilemektedir. FAO'ya göre, tahmini 20-30 milyon hektar alan tuzluluk nedeniyle ciddi şekilde bozulmaktadır (Leyva ve ark. 2011). Doğal koşullara ek olarak, son zamanlarda sulu tarım yapılan arazilerin büyük bir kısmında su tablalarının topraktaki tuzların yükselmesine ve konsantre hale gelmesine yol açmasıyla, tuzlulukla ilgili sorunlar artmıştır (Munns ve Tester 2008). Türkiye'de 2 milyon hektarlık ekilen alan, tuzluluk ve alkaliniteden etkilenmektedir (Güngör ve Erezol 1994; Yildirim ve ark. 2015)

Toprak tuzluluğu, su potansiyelini düşürerek, su ve besin maddelerinin alımı için gereken enerjiyi artırarak ozmotik strese neden olur. İyonik stres, duyarlı bitki dokularında sodyum ve klor iyonlarının giderek birikmesinden kaynaklanmaktadır (Munns ve Tester 2008; Flowers ve ark. 2010; Yildirim ve ark. 2015). Ayrica, tuzlar ve mineral besin maddeleri arasındaki etkileşimler, besin dengesizliklerine ve eksikliklerine neden olabilir (Yildirim ve ark. 2006). Tuzluluk, ROS oluşumunu artırır ve oksidatif stresi (Parida ve Das 2005) uyarır, bu da membranlara ve diğer hücresel yapılara önemli zarar verir (Gao ve ark. 2008). Tuz stresi, bitki fizyolojisini, hem bitki hem de hücresel seviyelerde, ozmotik ve iyonik stres yoluyla etkiler. Yüksek tuz konsantrasyonları, tohum 
çimlenmesini, fide büyümesini, bitkisel büyümeyi, çiçeklenmeyi ve meyve tutumunu olumsuz yönde etkileyebilir ve nihayetinde ekonomik verimi ve kaliteyi azaltabilir (Arora ve ark. 2008).

Bitkiler, plazma ve tonoplast membranlar boyunca sodyum taşınımının kontrolü, ozmotik ayarlama, ROS süpürücülerin aktif hale gelmesi ve vakoulde iyon birikimi dahil olmak üzere tuz stresine karşı hayatta kalmak ve adapte olmak için çok sayıda stratejiyi kullanırlar (Maggio ve ark. 2007; Mickelbart ve ark. 2015). Tuz stresi altında hücresel süreçlere aracılık etme yeteneği, stres, sinyal iletimi ve iyonik dengeyi sürdürmek için adaptasyon algısını gerektirir (Ji ve ark. 2013).

Tuz stresi altında aşırı ROS birikmesi oksidatif hasara neden olabilmekte ve NO modifiye edici antioksidan metabolizması yoluyla bitkilerde tuz stresinin hafifletilmesinde fonksiyonel bir molekül olarak kabul edilmektedir (Lin ve ark. 2012). NO uygulamalarıyla tuz stresi altında yetiştirilen pirinçte antioksidatif enzim aktivitesinin arttığı ve spesifik tuzluluk stresine direnç genlerinin ifadesi ile bitkilerin daha güçlü bir büyüme gösterdiği gözlenmiştir (Arasimowicz ve Floryszak-Wieczorek 2007). Benzer şekilde NO uygulamalarıyla, tuz stresinde yetiştirilen pirinç fidelerinde oksidatif zararların hafiflediği (Wu ve ark. 2011; Uchida ve ark. 2002) ve sekonder metabolit birikiminin arttığı bildirilmektedir (Bellin ve ark. 2013).

Tuzluluğun neden olduğu yan etkileri azaltmak için, çeşitli büyüme düzenleyiciler kullanılmaktadır. Bunlar arasında NO'nun, hem normal hem de stresli koşullar altında çeşitli metabolik yolların düzenlenmesinde rol oynadığı belirlenmiştir (Ahmad ve ark. 2016a,b; Ahmad ve ark. 2018). NO, antioksidan metabolizmasını, besin asimilasyonunu ve stres yanıtı genlerinin düzenlenmesini geliştirerek ROS kaynaklı oksidatif stresi azaltmaktadır (Fatma ve ark. 2014; Ahmad ve ark. 2016a,b). NO'nun, NaCl stresinde nohut (Cicer arietinum) bitkisinde antioksidan metabolizmayı teşvik ederek ve mineral asimilasyonunu sürdürerek büyümeyi düzenlediği tespit edilmiştir (Ahmad ve ark. 2018). Tuz stresi altında yetiştirilen mısır fidelerinde ve yoncada SNP (NO donorü) uygulamasının büyüme ve kuru ağırlığı artırdığı belirtilmiştir (Zhang ve ark. 2006).

Tuz stresine maruz kalan domates (Solanum lycopersicum L.) bitkilerinde NO uygulanmasının büyüme, antioksidan metabolizma, fizyo-biyokimyasal özellikler ve metabolit birikimi üzerine etkileri araştırılmıştır. Bitkilerin $\mathrm{NaCl}(200 \mathrm{mM})$ ile muamele edilmesi ile bitkide biyokütle, oransal su içeriği ve klorofil içeriği bakımından dikkate değer bir ölçüde olumsuz etkilenmiştir. İncelenen bu parametrelerin NO uygulaması ile olumlu etkilendiği, $200 \mathrm{mM} \mathrm{NaCl}$ tuz şartlarında, elektrolit sızıntısında, lipit peroksidasyonunda ve hidrojen peroksit üretiminde belirgin bir artış görüldüğü, ancak bunların NO uygulamasıyla azaldığı tespit edilmiştir. Tuz stresi, bitkide süperoksit dismutaz (SOD), katalaz (CAT), askorbat peroksidaz (APX), ve glutatyon redüktaz (GR) gibi antioksidan enzimlerin aktivitelerini artırarak antioksidan sistemin uyarılmasını tetiklemiştir. NO uygulanmasının da SOD, CAT, APX ve GR faaliyetlerinin aktivitelerinde daha da fazla bir artışa neden olduğu görülmüştür. Ayrıca NO uygulamasının, flavonoid, prolin ve glisin betain sentezini arttırdığı tespit edilmiştir. Sonuç olarak, NO’nun antioksidan metabolizmay1, osmolit sentezini ve metabolit birikimini teşvik ederek, domates bitkilerinin $\mathrm{NaCl}$ kaynaklı hasardan koruduğu bildirilmiştir (Ahmad ve ark. 2018).

Daha önceki çalışmalar NO uygulamalarının domates (Manai ve ark. 2014a; Manai ve ark. 2014b), pirinç (Habib ve ark. 2013), misır (Zhang ve ark. 2006) ve buğdayda tuza toleransın iyileştirilmesindeki rolünü ortaya koymuştur (Zheng ve ark. 2009). Zhao et al (2004) ve Zhang ve ark. (2006) tarafından tuz stresi altında büyütülen Phragmites communis Trin. ve misırda büyüme ortamına SNP eklenmesi ile plazma membranı $\mathrm{H}^{+}$-ATPase aktivitesini ve sonuçta $\mathrm{K}^{+} / \mathrm{Na}^{+}$oranını arttırdığı ifade edilmiştir. Ayrıca, NO uygulamalarının tuz stresi altında pirinçte tohum çimlenmesini artırdığı bildirilmiştir (Habib ve ark. 2010).

Tuzlu koşullarda yetiştirilen buğday (Triticum aestivum L.) da yapraktan farklı konsantrasyonda NO (0, 0.05 , 0.10 ve $0.15 \mathrm{mM}$ ) uygulamalarının tuzluluğun bitki gelişimi üzerinde oluşturduğu olumsuz etkiyi azalttığ ve fotosentetik aktiviteyi artırdığı, belirlenmiştir (Kausar ve Shahbaz 2013).

Benzer şekilde, NO donörü olarak farklı konsantrasyonlarda (0, 0.1 ve $0.2 \mathrm{mM})$ SNP uygulamalarının buğdayda tuz stresine toleransı artırıp artırmayacağı üzerine yürütülen bir çalışmada tuzluluğun, biyokütle ve tane veriminde önemli bir azalmaya neden olduğu, prolin (Pro), askorbik asit (AsA), hidrojen peroksit $\left(\mathrm{H}_{2} \mathrm{O}_{2}\right)$ ve malondialdehid (MDA) içeriklerini arttırdığı belirlenmiştir. Ayrıca, SNP uygulamasının tuz stresine bağlı oksidatif stresin bitki biyokütlesi ve tane verimi üzerindeki olumsuz etkilerinin azaltılmasında etkili olduğu bildirilmiştir. Aynı çalışmada SNP uygulamalarının, tuz stresi uygulanmış buğday bitkilerinde SOD, POD ve CAT ve AsA, Pro ve toplam fenolik (TPC) içeriği gibi antioksidan enzimlerin aktivitelerini artırdığı tespit edilmiştir (Ali ve ark. 2017)

NO ile priming uygulamasının erken fide gelişimi aşamasında Jatropha curcas'da tuz toleransı üzerine etkisinin incelendiği bir çalışmada, uygulamaların tuz stresinin bitki gelişimi üzerine yaptığı olumsuz etkiyi azalttığı tespit 
edilmiştir. Çalışmada NO ile yapılan priming uygulamasının $\mathrm{Na}^{+}$ve $\mathrm{Cl}^{-}$birikiminde, $\mathrm{H}_{2} \mathrm{O}_{2}$ içeriği ve membran hasarında önemli bir azalmaya yol açtı̆̆ rapor edilmiştir. NO uygulanmış stresli fidelerdeki düşük oksidatif hasar, daha büyük glutatyon (GSH) ve AsA içerikleri ile CAT ve GR enzim aktivitelerini içeren güçlü bir antioksidan sistemin çalışmasına neden olmuştur. Sonuç olarak, NO primingi, etkili bir antioksidan sistemini indükleyerek, toksik iyon ve ROS birikimini sınırlamış ve böylelikle fide gelişimi sırasında J. curcas'ın tuz toleransını geliştirdiği bildirilmiştir (Gadelha ve ark. 2017)

Hıyarda hipokotil ve kök büyümesi ile antioksidan kapasitesi üzerine SNP 'nin etkilerinin incelendiği bir çalışmada, $100 \mathrm{mM} \mathrm{NaCl}$ şartlarında hıyar hipokotillerinde ve kökçüğünde $\mathrm{H}_{2} \mathrm{O}_{2}$ ve tiyobarbitürik asit-reaktif maddelerin (TBARS) birikiminin arttığı, ancak $100 \mu \mathrm{M}$ SNP uygulaması ile bunlarda azalma görüldüğü belirlenmiştir. Kök ucu hücrelerinin ultra strüktürü incelendiğinde, tuz stresinde mitokondri ve hücre duvarında bozulma olduğu ancak, SNP uygulaması ile ultrastrüktürdeki tuz stresinin neden olduğu bozulmanın görülmediği belirlenmiştir. Çalışma sonunda, NO uygulamalarının antioksidan kapasitesinin artması, hıyar hipokotillerinin ve radiküllerin büyümesi ve hücre stresine zarar vermesi gibi tuz stresinin zararının azaltılmasındaki işlevinden büyük ölçüde sorumlu olduğu sonucuna varılmıştır (Lin ve ark. 2012).

\section{Kuraklık ve NO Uygulamaları}

Kuraklık, Dünya'da en önemli tarımsal problemlerden biri olup, özellikle kurak ve yarı kurak bölgelerde bitkisel üretimi önemli ölçüde sınırlayan bir stres faktörüdür. Dünya tarımının beşte ikisi kurak alanlarda yapılmaktadır (FAO 2005). Evsel ve endüstriyel su gereksiniminin artışı ve suların kirlenmesi de tarımda kullanılan suyu tehdit etmektedir. Yapılan çalışmalar, önümüzdeki yıllarda kuraklık etkisinin daha da artacağını ve bu durumun tarımsal üretimi olumsuz etkileyeceğini bildirmektedir (Kijne 2006). Tüm dünyada olduğu gibi Türkiye'de küresel ısınmanın sonucu olarak özellikle su kaynaklarının zayıflaması, kuraklık ve çölleşme ile buna bağlı ekolojik bozulmalarla karşı karşıya olup, küresel ısınmanın potansiyel etkileri açısından risk grubu ülkeler arasındadır. Küresel iklim değişikliğinin, kurak ve yarı kurak alanların genişlemesine ek olarak kuraklı̆̆ın süresinde ve şiddetindeki artışlar, çölleşme süreçlerini, tuzlanma ve erozyonu da tetikleyeceği bildirilmektedir (Türkeş 1994).

Kuraklığın, bitki morfolojisinden moleküler seviyelere kadar bitki büyümesindeki tüm olaylar üzerine etkili olduğu birçok çalışmada gösterilmiştir (Farooq ve ark. 2009a). Kuraklık stresi, farklı bitkilerde, bu tür sınırlayıcı çevresel koşullara uyum sağlamalarına yardımcı olacak çeşitli fizyolojik, biyokimyasal ve moleküler tepkilere neden olur (Bajaj ve ark. 1999; Arora ve ark. 2002). Kurak koşullar fotosentetik aktivite üzerine olumsuz etki yapar, hücrede klorofil içeriğinin ve bileşenlerinin değişmesine neden olur ve fotosentetik kısımlara zarar verir (Escuredo ve ark. 1998). Ayrıca fotokimyasal aktiviteleri inhibe eder ve Calvin çemberindeki enzimlerin aktivitelerini azaltır (Monakhova ve Chernyadev 2002).

Yapılan bir çalışmada, yapay kuraklık şartlarında yetiştirilen pirinç (Oryza sativa) üzerinde $100 \mu \mathrm{M}$ SNP'in etkileri araştırılmıştır. Çalışmada, su potansiyelinin azalması durumunda AsA ve GSH içeriğinin, oksidatif hasara karşı güçlü bir antioksidan savunma bileşeni olarak arttığı tespit edilmiştir. NO uygulamaları, toplam çözünebilir fenol içerikleri ve phenylalanine ammonia layase (PAL) aktivitesini arttırmıştır. Çalışmada ayrıca, çeşitli antioksidan savunma enzimleri SOD, APX, CAT ve GR aktivitelerindeki artış, kuraklık koşullarının teşvik ettiği oksidatif hasara karşı koruyucu aktiviteyi gösterdiği belirtilmiş̧ir (Shehab 2010).

Tu ve ark. (2003), 0.1 mM SNP'in klorofil ve çözünebilir proteinlerin, özellikle de Rubisco'nun bozunmasının inhibisyonu ile buğday yapraklarının yaşlanmasını geciktirdiğini bulmuşlardır. Ayrıca, NO uygulamalarının buğday fidelerinin kuraklığa toleransını arttırdığı belirlenmiştir (Garcia-Mata ve Lamattina 2001). Yapılan çalışmalar absisik asit (ABA), $\mathrm{H}_{2} \mathrm{O}_{2}$ ve $\mathrm{NO}$ sinyal molekülleri arasında yakın fonksiyonel ilişki olduğunu göstermiştir (Arasimowicz ve Floryszak-Wieczorek 2007).

Diğer bir çalışmada kurak koşulların hıyarda (Cucumis sativus ) fide köklerinde NO üretimi üzerindeki etkisi araştırılmıştır. Kurak koşullara maruz kalan kök uçlarındaki hücrelerde NO sentezi olduğu belirlenmiştir. Aynı çalışmada, NO donörü olarak $100 \mu \mathrm{M}$ SNP ve $100 \mu \mathrm{M}$ S-nitrosoglutathione (GSNO) uygulamasıyla yaprak oransal su içeriğinin arttı̆̆ belirlenmiştir. NO uygulamalarının lipoxygenase (LOX) aktivitesini ve lipit peroksidasyonunu azalttığı, NO mekanizmasının bitkilerin dehidrasyonunun ilk aşamasında etkili mekanizmaların tetiklenmesine ve hıyar köklerindeki kuraklığın etkilerinin hafifletilmesine yardımcı olduğu belirlenmiş̧tir (Arasimowicz-Jelonek ve ark. 2009).

Pirinçte (Oryza sativa L.) kuraklık stresine toleransı arttırmak için NO'nun rolünün araştırıldığı bir çalışmada, NO donörü olan SNP, 50, 100 ve $150 \mu \mathrm{M}$ konsantrasyonlarda hem tohuma hem de yaprağa sprey olarak 
uygulanmıştır. Çalışmada kuraklık stresinin pirinçte bitki büyümesini ciddi şekilde azalttığı, ancak her iki NO yöntemi de stres etkilerini hafiflettiği, yapraktan $100 \mu \mathrm{M}$ SNP uygulamasının daha etkili olduğu tespit edilmiştir. Pirinçte kuraklığa toleransı, NO'nun sinyal yolu ile doku su potansiyelinin korunmasına, antioksidanların kapasitesinin artmasına, hücresel membranların stabilitesine ve fotosentetik kapasiteyi artırmasına bağlı olduğu ileri sürülmüştür (Farooq ve ark. 2009b). NO, oksidatif stres koşullarının yol açttğı zararlara karşı koruyucu olduğu kanıtlanmış birçok biyolojik yolakları olan çok aktif bir moleküldür. Yürütülen bir çalışmada, buğdayın (Triticum aestivum) su stresi koşullarına cevaben iki NO donörü (SNP ve S-nitroso-N-asetilpeniklamin) uygulamalarının etkisi araştıılmışıtır. Çalışmadan elde edilen sonuçlara göre uygulanan NO donörlerinin, bitkilerde şiddetli kuraklık stres koşullarına karşı artan bir tolerans sağlayabileceği belirlenmiştir (Carlos Garc1'a-Mata 2001).

Kuraklık stresinin neden olduğu oksidatif stres, kurak ve yarı kurak bölgelerde çim ekimi için önemli bir sinırlayıcı faktördür. 150,200 ve $250 \mu \mathrm{M}$ konsantrasyonlarında SNP uygulamalarının kuraklık stresi altında yetiştirilen Poa pratensis L. 'Balin', Lolium perenne L. 'Numan' ve Cynodon dactylon L. Pers., bitkileri üzerine etkilerine bakıldığı bir çalışmada, SNP uygulamalarının kuraklık stresi sırasında üç çim türünün antioksidan enzimlerinin aktivitesini önemli ölçüde artırdığı belirlenmiştir. CAT, peroksidaz (POD), SOD ve APX'in maksimum aktivitesi, $200 \mu \mathrm{M}$ SNP uygulamasında tespit edilmiştir (Rahimian Boogar ve ark. 2014).

\section{Ağır Metal Stresi ve NO Uygulamalarl}

Madencilik faaliyetlerindeki artış, fabrikalar ve artan endüstrileşme geniş alanları ağır metallerle bulaşık hale getirmektedir. Ağır metallerin bitkiler tarafından akümüle edilmesi ile bunları besin zincirine dahil olduğu bildirilmektedir (Rubio et al 1994). Ağır metal birikimi ve bitkiler üzerindeki etkileri üzerine yapılan çalışmalar, ağır metallerin güçlü bir fitotoksik olduğunu, büyüme inhibisyonuna ve bazı durumlarda ölüme neden olduğunu ortaya koymuştur (Prasad 1995; Salt 2001). Metaller bitkilerin yaşamsal olaylarının normal devam edebilmesi için gerekli elementlerdir. Bununla birlikte bazı metallerin kök bölgesinde aşırı bulunması, bitkiler için toksik etki meydana getirmektedir. Fazla olması durumunda bitkilerde büyüme ve verim bakımından olumsuz etki yapan bu metaller çoğunlukla kadmiyum $(\mathrm{Cd})$, krom $(\mathrm{Cr})$, çinko $(\mathrm{Zn})$, bakır $(\mathrm{Cu})$, kurşun $(\mathrm{Pb})$ ve nikel $(\mathrm{Ni})$ dir (Prasad ve Strazalka 2002). Bunlar bitkilerde kolayca birikebilmekte, bitki büyümesini ve besin maddesi alımını engelleyebilmektedirler (Brune ve ark. 1995). Söz konusu metaller gerek toksik etki yaparak gerekse bitkiler için demir gibi gerekli minerallerin yerine geçerek bunların bitki tarafından alımını engellemektedirler. Ağır metaller, bitkilerde aktif oksijen türlerini aktive ederek, klorofil ve dolayısı ile fotosentez oranında azalmaya neden olurlar. Diğer stres koşullarında olduğu gibi ağır metal stresi de bitki etilen seviyesini artırarak, kök ve sürgün gelişimini yavaşlatır, $\mathrm{CO}_{2}$ fiksasyonu azaltır ve şeker taşınımını sınırlarlar (Buchanan ve ark. 2000). Pek çok araştırmacı ağır metallerin oksidatif strese yol açan ROS oluşumunu uyardığını bildirmişlerdir (Loureiro ve ark. 2006; Hu ve ark. 2007; Gupta ve ark. 2009). Diğer taraftan, son yıllarda, yapılan çok sayıdaki çalışmada, NO'nun bitkilerde ağır metal toksisitesini hafifletme üzerindeki etkisi araştırılmıştır (Chen ve ark. 2010; Wang ve ark. 2013, Ismail 2012). NO uygulamalarının bitkilerde ağır metaller, etilen ve herbisitlerin yıkıcı etkisini azalttığı (Kopyra ve Gwóźdź 2003; Hung ve ark. 2002) CAT gibi enzimlerin aktivitelerinin artışına yol açarak bitkilerde Cd ve arsenik (As) gibi çeşitli ağır metallere toleransı artırdığı bildirilmiştir (Laspina ve ark. 2005; Singh ve ark. 2009; Jin ve ark. 2010).

SNP uygulamalarının mung fasulyesinde (Vigna radiata) As toksisitesine karşı koruyucu bir etkiye sahip olup olmadığı araştırılmıştır. Çalışmada $75 \mu \mathrm{M}$ SNP uygulamasının mung fasulyesinde tohum çimlenmesini ve bitki gelişimini önemli ölçüde iyileştirip, As birikimini azalttığı belirlenmiştir. Ayrıca, NO uygulamaları arsenikten kaynaklanan MDA ve $\mathrm{H}_{2} \mathrm{O}_{2}$ artı̧̧ını azaltırken CAT ve $\alpha$-amylase ve protease aktivitesini artırmış̧ır (Ismail 2012). Tohumları $10 \mu \mathrm{M}$ SNP solüsyonunda 24 saat boyunca bekletilen Lupinus luteus L. cv.Ventus'da Pb ve $\mathrm{Cd}$ ağır metal stresinin bitkide toprak altı ve toprak üstü aksamında yol açtığı olumsuz etkileri azalttığı, köklerde SOD aktivitesini artırdığı bildirilmiştir (Kopyra ve Gwóźdź 2003).

Ayçiçeğinde Cd stresinden kaynaklanan oksidatif stresin hafifletmesi amacıyla NO uygulamasının etkilerini incelemek amacıyla yapraktan $100 \mu \mathrm{M}$ SNP uygulanmıştır. Uygulama ile ağır metal stresinden kaynaklanan lipid peroksidasyonun ve toplam glutathione (GSH) artışının azaldığı tespit edilmiştir. Benzer şekilde stres ile ascorbate (ASC) içeriğindeki artışın da NO uygulaması ile azaldığı tespit edilmiştir. Araştırma sonunda NO uygulamasının Cd toksisitesine karşı olumlu etki gösterdiği ve bitkilerde ağır metal stresine karşı tolerans sağlayabileceği bildirilmiştir (Laspina ve ark. 2005).

NO bitkilerde toksik metallere karşı savunma tepkileri dahil olmak üzere birçok gelişimsel ve fizyolojik sürece katılan önemli bir gaz sinyal molekülüdür. Cd tarafindan indüklenen toksik etkilerin fotosentez üzerindeki rolü, hardal (Brassica juncea L.) bitkilerinde incelenmiştir. Bitkilerin $50 \mathrm{mM}$ Cd'ye maruz kalması, oksidatif stresi, 
bitki gelişimini ve fotosentetik aktiviteyi, klorofil floresansını ve klorofil içeriğini önemli ölçüde azaltmış, ancak $100 \mu$ M SNP uygulaması ile Cd'den kaynaklanan oksidatif stresi SOD, APX, GR ve indirgenmiş glutatyon stimülasyonu yoluyla azaltmıştır. SNP'in bitki büyümesini, fotosentezi ve klorofil içeriğini önemli ölçüde arttırdığı ve ROS, $\mathrm{H}_{2} \mathrm{O}_{2}$ ve TBARS birikimini azalttığı belirtilmiştir (Per ve ark. 2017).

Pirinçte Ni toleransının iyileştirilmesinde NO uygulamalarının etkisi araştırılmış, Ni stresinin bitki gelişimini olumsuz etkilediği, ancak NO uygulamalarının bu olumsuz etkiyi azalttığı tespit edilmiştir. Ni stresli bitkilerde $\mathrm{H}_{2} \mathrm{O}_{2}$, MDA ve elektrolit sızıntısının arttığı, NO uygulamasının bu parametrelerin azalmasına yol açtığı belirlenmiştir. NO uygulamaları ayrıca, Ni stresli bitkilerde antioksidan kapasitesini ve CAT, POD, APx, GR ve SOD genlerinin transkript seviyelerini artırdığı bildirilmiştir. Çalışma sonunda, NO'nun, toksisiteyi azaltmada etkili bir stres düzenleyici olduğu ileri sürülmüştür (Rizwan ve ark. 2018). Diğer bir ağır metal stresi ile ilgili çalışmada da NO uygulamalarının buğday, pirinç ve çavdarda Cd toksisitesinin zararlı etkilerini azalttığı belirlenmiştir (Singh ve ark. 2008; Wang ve ark. 2013; Mutlu ve ark. 2018).

\section{Düşük Sıcaklık ve NO Uygulamaları}

Bitkiler, tohum çimlenmesinden ürün elde edilmesine kadar olan tüm safhalarda çevre sıcaklığından maksimum seviyede etkilenirler. Büyümenin her safhası için optimum sıcaklık isteğine gereksinim duyarlar ve bu gereksinim türler hatta çeşitler arasında farklılık gösterebilmektedir. Optimumun altındaki sıcaklıklar, bitki büyümesini ve nihayetinde verimi olumsuz etkilemektedirler. Düşük sıcaklık tohum çimlenmesini ve çıkış1 yavaşlatır, su ve besin maddesi alımını sınırlar, toprak kaynaklı hastalıkların zararını artırır, çiçeklenmeyi, tohum oluşumunu ve meyve olgunlaşmasını olumsuz etkiler ve son olarak da bitkinin ölümüne neden olabilir (Pierce 1987). Sicak iklim bitki türleri düşük sıcaklıklara oldukça hassastırlar (Decoteau 2000). Düşük sıcaklı̆ğın hücrenin tüm metabolik sistemini etkileyeceği hatta su stresine neden olduğu bildirilmiştir (Kratsch ve Wise 2000). Düşük sıcaklı̆̆ın ayrıca, bitkilerde organik asitleri, şekerleri, fenolik maddeleri, fosfolipidleri, protein ve ATP'yi de etkilediği hücre membranlarında zararlanmaya yol açtı̆̆ı rapor edilmiştir (Lyons 1973).

Düşük sıcaklık stresi, birçok bitkinin büyümesini, üretkenliğini ve coğrafi dağılımını sınırlayan başlıca abiyotik streslerden biridir (Esim ve Atıcı 2014; Kuşvuran ve ark. 2013). Diğer streslere benzer şekilde, düşük sıcaklığa maruz kalma, bitki hücrelerinde süperoksit radikali $\left(\mathrm{O}^{2}\right.$.-), $\mathrm{H}_{2} \mathrm{O}_{2}$ ve hidroksil radikali $(\mathrm{OH}-)$ gibi $\mathrm{ROS}$ 'lerin aşırı üretimini indükler. ROS lipid peroksidasyonuna, proteinlerin ve nükleik asitlerin oksidatif modifikasyonuna neden olabilir (Liu ve ark. 2010; Fan ve ark. 2014). Bununla birlikte, bitkiler ROS tarafindan başlatılan hasarı hafifletmek ve onarmak için spesifik koruyucu mekanizma geliştirmişlerdir. En önemli ROS temizleme mekanizmaları, SOD, POD, CAT, APX ve GR'dan oluşan enzimatik sistem ve enzimatik olmayan AsA ve glutatyon (GSH) dur (Almeselmani ve ark. 2006; Yin ve ark. 2008).

Bitkilerde düşük sıcaklığa toleransın, ROS süpürme sistemlerinin aktivasyonu ile pozitif olarak ilişkili olduğu belirtilmektedir. Yapılan araştırmalar, antioksidan sistemlerin, stresin yarattığı oksidatif hasara karşı bitkileri korumada önemli rol oynadığını göstermiştir (Esim ve Atıcı 2014). Bu nedenle, bitkilerin organlarındaki antioksidan enzimlerin aktivitesinin arttırılması, bitkinin düşük sıcaklık stresine karşı toleransının iyileştirilmesi için gereklidir. Bazı araştırmalar, NO'nun abiyotik streslere karşı koruyucu etkisinin, bitkilerde NO'nun ROS'u süpürücü etkisi ile yakından ilişkili olduğunu göstermiştir (Fan ve ark. 2014). Arabidopsis thaliana'da düşük sıcaklığa adaptasyonun endojen NO düzeyini artırdığını ve NO üretiminin düşük sıcaklığa toleransta önemli bir rol oynadığını ileri sürülmüştür (Siddiqui ve ark. 2011).

NO donörü olarak SNP uygulamalarının düşük stres şartlarında yetiştirilen çin lahanası fidelerinde bitki gelişimi ve antioksidan enzim aktivitesi üzerine etkilerinin incelendiği bir çalışmada, düşük sıcaklığın çin lahana fidelerinde bitki gelişimini önemli ölçüde azalttığı ancak yapraktan sprey şeklinde SNP uygulamasıyla bu olumsuz etkinin önemli ölçüde azaldığı tespit edilmiştir. Düşük sıcaklı̆̆ın ayrıca CAT hariç enzim aktivitesini, elektrolit sızıntı ve MDA'yı artırdığı bununla birlikte klorofil içeriğini azalttığı belirlenmiştir. NO uygulaması ile düşük sıcaklık stresi altında yetiştirilen çin lahanası fidelerinde antioksidan aktivitesi, klorofil ve protein içeriği artarken, elektrolit sızıntı ve MDA ise azalma göstermiştir (Fan ve ark. 2014).

Dışarıdan uygulanan NO'nun, düşük sıcaklık stresine maruz kalan buğday (Esim ve ark. 2014) ve mısır (Esim ve Atıcı 2014) fidelerinde antioksidan enzim aktivitelerini uyararak soğuk toleransını artırdığı da rapor edilmiştir (Öcal Özdamar ve ark. 2016). 
Artan atmosferik $\mathrm{CO}_{2}$ ve diğer sera gazları yeryüzü sıcaklığında $1.5-5.9{ }^{\circ} \mathrm{C}$ artışa neden olmuştur. Araştırmalar, gelecekte söz konusu sera gazlarının etkisinin daha da artarak tarımsal üretimi olumsuz etkileyeceğini ileri sürmektedir (Kijne 2006). Bitkiler yüksek gün ve gece sıcaklığına ya da yüksek hava ve toprak sıcaklıklarına farklı şekilde tepki gösterirler. Bitki türleri arasında da yüksek sıcaklıklara duyarlılık bakımından büyük farklılıklar bulunmaktadır. Serin iklim türleri sıcak iklim türlerinden daha fazla sıcak havaya duyarlıdır. Ayrıca sıcaklığın süresi, derecesi ve bitkinin gelişme dönemi de zararın derecesini etkilemektedir (Hall 2001).

Yüksek sıcaklık, birçok bitki türünde çimlenme ve çıkışı olumsuz etkileyebilmektedir. Vejetatif gelişme periyodunda yüksek sıcaklığın, fotosentez oranını, karbondioksit asimilasyonunu ve metobolik aktiviteyi azalttığı bildirilmiştir (Al-Khatib ve Paulsen 1999; Sam ve ark. 2001). Yüksek sıcaklıklar ayrıca membran stabilitesini bozabilmekte, yapraklarda su stresindeki semptomlara benzer şekilde nekrotik lekeler meydana getirerek nihayetinde erken ölümlere neden olabilmektedir (Hall 2001). Sicaklık stresi bitkilerde besin alımını da olumsuz etkilemektedir (Rosa ve ark. 2003). Generatif gelişme periyodunda ise yüksek sıcaklık, çiçek tozu çimlenmesi, döllenme, çiçeklenme, tohum ve meyve oluşumunu olumsuz etkileyerek verimde önemli azalmalara neden olabilmektedir (Hall 1992; Hall 1993).

Diğer stresler gibi, yüksek sıcaklık stresi de ürün veriminde önemli bir olumsuz etkiye sahiptir. Yüksek sıcaklık bitkilerde oksidatif stres, lipid peroksidasyonu, membran hasarı, protein y1k1mı, enzim inaktivasyonu, pigment ağartma ve DNA ipliklerinin bozulmasına neden olmaktadır (Suzuki ve Mittler 2006). Yonca hücrelerinin yüksek sıcaklığa maruz kalması NO sentezinin artmasına neden olurken, domates, buğday ve mısırda eksojen NO uygulaması ile soğuk toleransının arttığı görülmüştür (Neill ve ark. 2003). Yoncada kısa süreli sıcaklık uygulaması NO üretimini artırmıştır (Leshem 2000). Bu etkinin, NO'nun antioksidatif etkisiyle ilişkili olması mümkündür (Neill ve ark. 2002). Bouchard ve Yamasaki (2008; 2009), sıcaklık stresinin NO üretimini uyardığını ifade etmişlerdir.

NO uygulamaları yüksek sıcaklık stresi altında kamış kalluslarında elektrolit sızıntısını bitki gelişimindeki yavaşlamayı ve hücre canlılığındaki azalmayı önemli düzeyde gerilemiştir. NO uygulamaları SOD, APX, CAT ve POD gibi antioksidan enzimlerinin aktivitelerini artırmıştır (Song ve ark. 2006). Yapılan diğer bir çalışmada, düşük sıcaklık stresine maruz bırakılan buğdaylarda $\mathrm{NO}$ uygulamalarının $\mathrm{H}_{2} \mathrm{O}_{2}$ ve $\mathrm{O}_{2}$ ile $\mathrm{MDA}$ miktarını azalttığ 1 tespit edilmiştir (Esim ve Atıcı 2014).

Song ve ark. (2006), SNP ve S-nitroz-N-asetil penisilamin uygulamasının, yüksek sıcaklık stresine bağlı elektrolit sızıntısı artışı, büyüme baskılanmasını ve hücre canlılığı azalmasını önemli ölçüde azalttığını ve ayrıca SOD, APX, CAT ve POD aktivitelerini artırdığını belirlemişlerdir. Bu sonuçlar, NO'nun, 1sı stresinin neden olduğu oksidatif stresten nasıl etkili bir şekilde koruyabildiğini ve NO'nun, 1s1 stresinde aktif oksijen tutucu enzimlerin aktive edilmesinde bir sinyal olarak hareket edebileceğini göstermektedir (Siddiqui ve ark. 2011). Başka bir çalışmada da ekzojen olarak uygulanan NO'nun, fotosentezi 1sı stresi altında koruduğu bildirilmiştir (Song ve ark. 2013),

Yürütülen başka bir çalışmada NO uygulamasının yüksek sıcaklık stresinde yetiştirilen pirinç fidelerinin daha fazla yeşil yaprak dokusunun hayatta kalmasına izin verdiği ve fotosistem II için daha yüksek kuantum veriminin sağlandığı tespit edilmiştir. NO uygulaması ayrıca, sadece ROS süpürücü enzim aktivitelerini değil, aynı zamanda sükroz-fosfat sentaz, $\Delta$-pyrrolin-5-karboksilat syntaz ve 1sı şoku proteinini kodlayan stres ile ilişkili genler için transkriptlerin ifadesini de ortaya çıkardığı belirlenmiştir. Sonuçta, NO'nun pirinç fidelerinde yüksek sıcaklık toleransını, yanıt için sinyal molekülleri olarak hareket ederek artırabildiğini göstermektedir (Uchida ve ark. 2002)

\section{Sonuç ve Öneriler}

Kuşkusuz, biyoaktif bir molekül olan NO, bitkilerde çok sayıda fizyolojik süreçte geniş bir yelpazede önemli bir rol oynar. Bununla birlikte, çalışmaların çoğu (a) bitki hormonları, besin maddeleri ve metaller ile etkileşimde sinyalleme molekülü olarak NO’nun rolü (b) bitkilerde NO aracılı savunma geni düzenlemesi, (c) farklı hücrelerde veya bitki organlarında içsel NO fonksiyonu ve (d) NO'nun bitkide biyosentez yolakları üzerinde yoğunlaşmıştır.

Halen daha NO ile ilgili çok sayıda cevapsız soru ve daha fazla araştırma için önemli alanlar bulunmaktadır. NO'nun üretildiği mekanizmalar hala büyük ölçüde çözülmemiş durumda ve farklı durumlarda farklı bitki hücreleri tarafından nasıl yapıldığının açıklığa kavuşturulması gerekmektedir. 


\section{Kaynaklar}

Ahmad P, Abdel Latef AA, Hashem A, Abd Allah EF, Gucel S, Tran LSP (2016a). Nitric oxide mitigates salt stress by regulating levels of osmolytes and antioxidant enzymes in chickpea. Front. Plant Sci. 7: 347.

Ahmad P, Rasool S, Gul A, Sheikh SA, Akram NA, Ashraf M, Kazi AM, Gucel S (2016b). Jasmonates: multifunctional roles in stress tolerance. Front. Plant Sci. 7: 813.

Ahmad P, Ahanger MA, Alyemeni MN, Wijaya L, Alam P, Ashraf M (2018). Mitigation of sodium chloride toxicity in Solanum lycopersicum L. by supplementation of jasmonic acid and nitric oxide. J. Plant Interact. 13: 64-72.

Al-Khatib K, Paulsen GM (1999). High-temperature effects on photosynthetic processes in temperate and tropical cereals. Crop Sci. 39: 119-125.

Ali Q, Daud MK, Haider MZ, Ali S, Rizwan M, Aslam N, Noman A, Iqbal N, Shahzad F, Deeba F, Ali I, Zhu SJ (2017). Seed priming by sodium nitroprusside improves salt tolerance in wheat (Triticum aestivum L.) by enhancing physiological and biochemical parameters. Plant Physiol. Biochem. 119: 50-58.

Almeselmani M, Deshmukh PS, Sairam RK, Kushwaha SR, Singh TP (2006). Protective role of antioxidant enzymes under high temperature stress. Plant Sci. 171: 382-388.

Arasimowicz M, Floryszak-Wieczorek J (2007). Nitric oxide as a bioactive signalling molecule in plant stress responses. Plant Sci. 172: 876-887.

Arasimowicz-Jelonek M, Floryszak-Wieczorek J, Kubiś J (2009). Involvement of nitric oxide in water stressinduced responses of cucumber roots. Plant Sci. 177: 682-690.

Arora A, Sairam RK, Srivastava GC (2002). Oxidative stress and antioxidative systems in plants. Curr. Sci. 82:1227-1238.

Arora N, Bhardwaj R, Sharma P, Arora HK (2008). Effects of 28-homobrassinolide on growth, lipid peroxidation and antioxidative enzyme activities in seedlings of Zea mays L. under salinity stress. Acta Physiol. Plant. 30:833-839.

Arora D, Bhatla SC (2017). Melatonin and nitric oxide regulate sunflower seedling growth under salt stress accompanying differential expression of Cu/Zn SOD and Mn SOD. Free Radic. Biol. Med. 106: 315328.

Bajaj S, Jayaprakash T, Li L, Ho TH, Wu R (1999). Transgenic approaches to increase dehydration-stress tolerance in plants. Mol. Breed. 5:493-503.

Begara-Morales JC, Sanchez-Calvo B, Chaki M, Valderrama R, Mata-Perez C, Lopez-Jaramillo J, Padilla MN, Carreras A, Corpas FJ, Juan Barroso B (2014). Dual regulation of cytosolic ascorbate peroxidase (APX) by tyrosine nitration and S-nitrosylation. J. Exp. Bot. 65: 527-538.

Bellin D, Asai S, Delledonne M, Yoshioka H (2013). Nitric oxide as a mediator for defense responses. Mol. Plant Microbe Interact. 26: 271-277.

Boyer JS (1982). Plant productivity and environment potential for increasing crop plant productivity, genotypic selection. Sci. 218: 443-448.

Bouchard JN, Yamasaki H (2008). Heat stress stimulates nitric oxide production in symbiodinium microadriaticum: a possible linkage between nitric oxide and the coral bleaching phenomenon. Plant Cell Physiol. 49: 641-652.

Bouchard JN, Yamasaki H (2009). Implication of nitric oxide in the heat-stress-induced cell death of the symbiotic alga Symbiodinium microadriaticum. Marine Biol. 156: 2209-2220.

Brune A, Urbach W, Dietz KJ (1995). Differential toxicity of heavy metals is partly related to a loss of preferential extraplasmic compartmentation: a comparison of Cd-, Mo-, Ni-, and Zn-stress. New Phytologist 129: 404-409.

Buchanan BB, Gruissen W, Jones RL (2000). Biochemistry and molecular biology of plants. Rockville: Amer. Soc. Plant Physiol. pp. 1-367.

Carlos Garcı'a-Mata LL (2001). Nitric oxide induces stomatal closure and enhances the adaptive plant responses against drought stress. Plant Physiol. 126: 1196-1204.

Chen F, Wang F, Sun HY, Cai Y, Mao WH, Zhang GP, Vincze E, Wu FB (2010). Genotype-dependent effect of exogenous nitric oxide on Cd-induced changes in antioxidative metabolism, ultrastructure, and photosynthetic performance in barley seedlings (Hordeum vulgare). J Plant Growth Regul. 29: 394408.

Corpas FJ, Barroso JB (2015). Nitric oxide from a “green” perspective. Nitric Oxide. 45: 15-19.

Denby K, Gehring C (2005). Engineering drought and salinity tolerance in plants: lessons from genome-wide expression profiling in Arabidopsis. Trends in Biotechnol. 23(11): 547-552.

Decoteau DR (2000). Vegetable Crops. Prentice-Hall Inc. New Jersey, USA.

Esim N, Atici O (2014). Nitric oxide improves chilling tolerance of maize by affecting apoplastic antioxidative enzymes in leaves. Plant Growth Regul. 72: 29-38. 
Esim N, Atici O, Mutlu S (2014). Effects of exogenous nitric oxide in wheat seedlings under chilling stress. Toxicol Ind Health. 30: 268-274.

Escuredo IP, Arrese-Igor C, Becana M (1998). Oxidative damage in pea plants exposed to water deficit or paraquat. Plant Physiol. 116:173-181.

Fan H, Du C, Xu Y, Wu X (2014). Exogenous nitric oxide improves chilling tolerance of Chinese cabbage seedlings by affecting antioxidant enzymes in leaves. Hortic. Environ. Biotechnol. 55: 159-165.

FAO (2005). Properties and Management of Dry Lands.

Farooq M, Wahid A, Kobayashi N, Fujita D, Basra SMA (2009a). Plant drought stress: effects, mechanisms and management. Agron. Sus. Develop. 29: 185-212.

Farooq M, Basra SMA, Wahid A, Rehman H (2009b). Exogenously applied nitric oxide enhances the drought tolerance in fine grain aromatic rice (Oryza sativa L.). J. Agron. Crop Sci. 195: 254-261.

Fatma M, Asgher M, Masood A, Khan NA (2014). Excess sulfur supplementation improves photosynthesis and growth in mustard under salt stress through increased production of glutathione. Environ. Exp. Bot. 107: 55-63.

Flowers T, Galal H, Bromham L (2010). Evolution of halophytes: multiple origins of salt tolerance in land plants. Funct. Plant Biol. 37:604-612.

Gao S, Ouyang C, Wang S, Xu Y, Tang L, Chen F (2008). Effects of salt stress on growth, antioxidant enzyme and phenylalanine ammonia-lyase activities in Jatropha curcas L seedlings. Plant Soil Environ. 54: 374-381.

Garcia-Mata C, Lamattina L (2001). Nitric oxide induces stomatal closure and enhances the adaptive plant responses against drought stress. Plant Physiol. 126: 1196-1204.

Gadelha CG, Miranda RD, Alencar NLM, Costa JH, Prisco JT, Gomes E (2017). Exogenous nitric oxide improves salt tolerance during establishment of Jatropha curcas seedlings by ameliorating oxidative damage and toxic ion accumulation. J. Plant Physiol. 212: 69-79.

Gupta M, Sharma P, Sarin NB, Sinha AK (2009). Differential response of arsenic stress in two varieties of Brassica juncea L. Chemosphere. 74:1201-1208.

Güngör Y, Erezol Z (1994). Drenaj ve arazi 1slahi. Ders Kitabi. Ankara: Ankara University.

Gürel A, Avcıoğlu R (2001). Bitkilerde strese dayanıklılık fizyolojisi, pp.308-313, In: Bitki Biyoteknolojisi II, Genetik Mühendisliği ve Uygulamaları, 21. bölüm. Özcan S, Gürel E, Babaoğlu M, (eds). Konya.

Habib N, Ashraf M, Ahmad MSA (2010). Enhancement in seed germinability of rice (Oryza sativa L.) by presowing seed treatment with nitric oxide (NO) under salt stress. Pak. J. Bot. 42: 4071-4078.

Habib N, Ashraf M, Shahbaz M (2013). Effect of exogenously applied nitric oxide on some key physiological attributes of rice (Oryza sativa L.) plants under salt stress. Pak. J. Bot. 45: 1563-1569.

Hall AE (1992). Breeding for heat tolerance. Plant Breed. Rev. 10: 129-168.

Hall AE (1993). Physiology and breeding for heat tolerance in cowpea, and comparison with other crops, pp: 271-284. In: Adaptation of food crops to temperature and water stress, Kuo CG (ed.), Publ. No. 93410, Asian Vegetable Research and Development Center, Shanhua, Taiwan.

Hall AE (2001). Crop responses to environment. CRC Press LLC, Boca Raton, Florida.

Hayat S, Hasan SA, Mori M, Fariduddin Q, Ahmad A (2010). Nitric oxide: chemistry, biosynthesis, and physiological role. Nitric Oxide in Plant Physiology. GmbH and Co. KGaA. Wiley-VCH Verlag, Weinheim, Germany, pp. 15-21.

Hu K, Hu LY, Li YH, Zhang FQ, Zhang H (2007). Protective roles of nitric oxide on germination and antioxidant metabolism in wheat seeds under copper stress. Plant Growth Regul. 53:173-183.

Hung KT, Chang CJ, Kao CH (2002). Paraquat toxicity is reduced by nitric oxide in rice leaves. J. Plant Physiol. 159: $159-166$.

Ismail GSM (2012). Protective role of nitric oxide against arsenic-induced damages in germinating mung bean seeds. Acta Physiologiae Plantarum. 34: 1303-1311.

Ji H, Pardo JM, Batelli G, Van Oosten MJ, Bressan RA, Li X (2013). The salt overly sensitive (SOS) pathway: established and emerging roles. Mol. Plant. 6: 275-286.

Jin J, Xu Y, Huang Y (2010). Protective effect of nitric oxide against arsenic-induced oxidative damage in tall fescue leaves. Afr. J. Biotechnol. 11:1619-1627

Kalefetoğlu T, Ekmekçi Y (2005). The effects on drought on plants and tolerance mechanisms. Gazi Uni. J. Sci. 18: 723-740.

Kausar F, Shahbaz M (2013). Interactive effect of foliar application of nitric oxide (NO) and salinity on wheat (Triticum aestivum L.). Pak. J. Bot. 45: 67-73.

Kijne JW (2006). Abiotic stress and water scarcity: Identifying and resolving conflicts from plant level to global level. Field Crops Research. 97: 3-18.

Kopyra M, Gwóźdź EA (2003). Nitric oxide stimulates seed germination and counteracts the inhibitory effect of heavy metals and salinity on root growth of Lupinus luteus. Plant Physiol. Biochem. 41: 1011-1017.

Kratsch HA, Wise RR (2000). The ultrastructure of chilling stress. Plant, Cell and Environ. 23: 337-350. 
Kusvuran S, Ellialtioglu S, Polat Z (2013). Antioxidative enzyme activity, lipid peroxidation, and proline accumulation in the callus tissues of salt and drought tolerant and sensitive pumpkin genotypes under chilling stress. Hort. Environ. Biotechnol. 54: 319-325.

Laspina NV, Groppa MD, Tomaro ML, Benavides MP (2005). Nitric oxide protects sunflower leaves against Cd-induced oxidative stress. Plant Sci. 169: 323-330.

Leshem YY (2000). Nitric oxide in plants. Occurence, function and use. Kluwer Academic Publishers, Boston

Leyva R, Sánchez-Rodríguez E, Ríos JJ, Rubio-Wilhelmi MM, Romero L, Ruiz JM, Blasco B (2011). Beneficial effects of exogenous iodine in lettuce plants subjected to salinity stress. Plant Sci. 181:195-202.

Lin Y, Liu Z, Shi Q, Wang X, Wei M, Yang F (2012). Exogenous nitric oxide (NO) increased antioxidant capacity of cucumber hypocotyl and radicle under salt stress. Scientia Horticulturae. 142: 118-127.

Lipton SA, Choi YB, Pan ZH, Lei SZ, Chen HS, Sucher NJ, Loscalzo J, Singel DJ, Stamler JS (1993). A redoxbased mechanism for the neuroprotective and neurodestructive effects of nitric oxide and related nitroso-compounds. Nature. 364:626-632.

Liu YJ, Jiang HF, Zhao ZG, An LZ (2010). Nitric oxide synthase like activity-dependent nitric oxide production protects against chilling-induced oxidative damage in Chorispora bungeana suspension cultured cells. Plant Physiol. Biochem. 48: 936-944.

Liu S, Dong YJ, Xu LL, Kong J, Bai XY (2013). Roles of exogenous nitric oxide in regulating ionic equilibrium and moderating oxidative stress in cotton seedlings during salt stress. J. Soil Sci. Plant Nutr. 13: 929941.

Loureiro S, Santos C, Pinto G, Costa A, Monteiro M, Nogueira AJA, Soares AMVM (2006). Toxicity assessment of two soils from Jales Mine (Portugal) using plants: growth and biochemical parameters. Arch. Environ. Contam. Toxicol. 50:182-190.

Lyons J M (1973). Chilling injury in plants. Ann. Rev. Plant Physiol. 24: 445-466.

Maggio A, Raimondi G, Martino A, De Pascale S (2007). Salt stress response in tomato beyond the salinity tolerance threshold. Environ. Exp. Bot. 59: 276-282.

Mahajan S, Tuteja N (2005). Cold, salinity ve drought stres: an overwiev. Arch. Biochem. Biophysics. 444: 139158.

Małgorzata Kopyra EAG (2004). The role of nitric oxide in plant growth regulation and responses to abiotic stresses. Acta Physiologiae Plantarum. 26: 459-472.

Manai J, Gouiab H, Corpasa FJ (2014a). Redox and nitric oxide homeostasis are affected in tomato (Solanum lycopersicum) roots under salinity-induced oxidative stress. J. Plant Physiol. 171: 1028-1035.

Manai J, Kalai T, Gouia H, Corpas FJ (2014b). Exogenous nitric oxide (NO) ameliorates salinity-induced oxidative stress in tomato (Solanum lycopersicum) plants. J. Soil Sci. Plant Nutr. 14 (2): 433-446.

Mickelbart MV, Hasegawa PM, Bailey-Serres J (2015). Genetic mechanisms of abiotic stress tolerance that translate to crop yield stability. Nature Reviews Genetics. 16: 237-251.

Monakhova OF, Chernyadev II (2002). Protective role of kartolin-4 in wheat plants exposed to soil drought. Appl. Environ. Microbiol. 38: 373-380.

Munns R, Tester M (2008). Mechanisms of salinity tolerance. Annu. Rev. Plant Biol. 59: 651-681.

Mutlu F, Yurekli F, Kirecci O, Dengiz F (2018). Investigation of antioxidant enzyme activities in wheat (Triticum aestivum L.) cultivars depending on nitric oxide application under cadmium stress. Fresenius Environ. Bull. 27: 421-429.

Neill SJ, Desikan R, Clarke A (2002). Hydrogen peroxide and nitric oxide as signaling molecules in plants. J. Exp. Bot. 53: 1237-1242

Neill S, Desikan R, Hancock JT (2003). Nitric oxide signalling in plants. New Phytol. 159: 11-35

Öcal Özdamar F, Baysal Furtana G, Ellialtioğlu ŞŞ, Tipirdamaz R (2016). Hidrojen peroksit ve nitrik oksit ilişkisinin bitkilerde abiyotik stres toleransındaki rolü. Tarla Bitkileri Merkez Araştırma Enstitüsü Dergisi. 25p.

Parida AK, Das AB (2005). Salt tolerance and salinity effects on plants: a review. Ecotoxicol. Environ. Safe. 60: 324-349.

Per TS, Masood A, Khan NA (2017). Nitric oxide improves S-assimilation and GSH production to prevent inhibitory effects of cadmium stress on photosynthesis in mustard (Brassica juncea L.). Nitric OxideBiol. Chem. 68: 111-124.

Pierce LC (1987). Vegetables. Characteristics, Production and Marketing. John Willey and Sons Inc. 433 p. USA.

Prasad MNV, Strazalka K (2002). Physiology and biochemistry of metal toxicity and tolerance in plants. Dordrecht, Kluwer Academic Publishers, 432 p. ISBN 1-40-200468-0.

Prasad MNV (1995). Cadmium toxicity and tolerance in vascular plants, Environ. Exp. Bot. 35: 525-545.

Rahimian Boogar A, Salehi H, Jowkar A (2014). Exogenous nitric oxide alleviates oxidative damage in turfgrasses under drought stress. South Afric. J. Bot. 92: 78-82. 
Rizwan M, Mostofa MG, Ahmad MZ, Imtiaz M, Mehmood S, Adeel M, Dai ZH, Li ZY, Aziz O, Zhang YH, Tu SX (2018). Nitric oxide induces rice tolerance to excessive nickel by regulating nickel uptake, reactive oxygen species detoxification and defense-related gene expression. Chemosphere. 191: 23-35.

Rosa M, Rivero ES, Ruiz JM, Romero L (2003). Influence of temperature on biomass, iron metabolism and some related bioindicators in tomato and watermelon plants. J. Plant Physiol. 160: 1065-1071.

Rubio MI, Escrig I, Martínez-Cortina C, López-Benet FJ, Sanz A (1994). Cadmium and nickel accumulation in rice plants. Effects on mineral nutrition and possible interactions of abscisic and gibberellic acids. Plant Growth Regul. 14 (2): 151-157.

Salt D (2001). Responses and adaptations of plants to metal stress, pp. 159-179. In: Molecular Analysis of Plant Adaptations to the Environment. Hawkesford MJ (ed.), Kluwer Academic Publishers, Dordrecht,

Sam O, Nunez M, Ruiz-Sancchez MC, DellAmico J, Falcon V, DeLaRosa MC, Seoane J (2001). Effect of a brassinosteroid analogue and high temperature stres on leaf ultrastructure of Lycopersicon esculentum. Biologia Plantrum. 44 (2): 213-218.

Shehab GG, Ahmed OK, El-Beltagi HS (2010). Effects of various chemical agents for alleviation of drought stress in rice plants (Oryza sativa L.). Not. Bot. Horti Agrobot. Cluj-Na. 38: 139-148.

Siddiqui MH, Al-Whaibi MH, Basalah MO (2011). Role of nitric oxide in tolerance of plants to abiotic stress. Protoplasma. 248: 447-455.

Singh HP, Batish DR, Kaur G, Arora K, Kohli RK (2008). Nitric oxide (as sodium nitroprusside) supplementation ameliorates Cd toxicity in hydroponically grown wheat roots. Environ. Exp. Bot. 63: 158-167.

Singh HP, Kaur S, Batish DR, Sharma VP, Sharma N, Kohli RK (2009). Nitric oxide alleviates arsenic toxicity by reducing oxidative damage in the roots of Oryza sativa (rice). Nitric Oxide. 20: 289-297.

Song L, Ding W, Zhao M, Sun B, Zhang L (2006). Nitric oxide protects against oxidative stress under heat stress in the calluses from two ecotypes of reed. Plant Sci. 171: 449-458.

Song L, Yue L, Zhao H, Hou M (2013). Protection effect of nitric oxide on photosynthesis in rice under heat stress. Acta Physiol. Plant. 35: 3323-2333.

Suzuki N, Mittler R (2006). Reactive oxygen species and temperature stresses: a delicate balance between signaling and destruction. Physiol Plant. 126: 45-51.

Tu J, Shen WB, Xu LL (2003) Regulation of nitric oxide on ageing processes of wheat leaves. Acta Botanica Sinica. 45:1057-1061.

Türkeş M (1994). Artan sera etkisinin Türkiye üzerindeki etkileri. Tübitak Bilim ve Teknik Dergisi. 321: 71.

Uchida A, Jagendorf AT, Hibino T, Takabe T, Takabe T (2002). Effects of hydrogen peroxide and nitric oxide on both salt and heat stress tolerance in rice. Plant Sci. 163: 515-523.

Wang QH, Liang X, Dong YJ, Xu LL, Zhang XW, Hou J, Fan ZY (2013). Effects of exogenous nitric oxide on cadmium toxicity, element contents and antioxidative system in perennial ryegrass. Plant Growth Regul. 69: 11-20.

Wu X, Ding H, Zhu W, Zhang H, Zhang HJ (2011). Exogenous nitric oxide protects against salt-induced oxidative stress in the leaves from two genotypes of tomato (Lycopersicom esculentum Mill.). Acta Physiol. Plant. 23: 304-307.

Yildirim E, Taylor AG, Spittler TD (2006). Ameliorative effects of biological treatments on growth of squash plants under salt stress. Sci. Hortic. 111:1-6.

Yildirim E, Ekinci M, Turan M, Dursun A, Kul R, Parlakova F (2015). Roles of glycine betaine in mitigating deleterious effect of salt stress on lettuce (Lactuca sativa L.). Arch. Agron. Soil Sci. 61: 1673-1689.

Yin H, Chen Q, Yi M (2008). Effects of short-term heat stress on oxidative damage and responses of antioxidant system in Lilium longiflorum. Plant Growth Regul. 54: 45-54.

Zhang Y, Wang L, Liu Y, Zhang Q, Wei Q, Zhang W (2006). Nitric oxide enhances salt tolerance in maize seedlings through increasing activities of protonpump and $\mathrm{Nap} / \mathrm{Hp}$ antiport in the tonoplast. Planta. 224: 545-555.

Zhao L, Zhang F, Guo J, Yang Y, Li B, Zhang L (2004). Nitric oxide functions as a signal in salt resistance in the calluses from two ecotypes of reed. Plant Physiol. 134: 849-857.

Zheng C, Jiang D, Liu F, Dai T, Liu W, Jing Q, Cao W (2009). Exogenous nitric oxide improves seed germination in wheat against mitochondrial oxidative damage induced by high salinity. Environ. Exp. Bot. 67: 222-227. 